\title{
Una mirada personalista de la obra Pinocho de Collodi: ser persona, la libertad, el vértigo y el amor ${ }^{1}$
}

\author{
Gabriel Quesada Mora \\ Universidad de Costa Rica \\ Editorial PROMESA, Costa Rica
}

\begin{abstract}
Resumen
El presente trabajo estudiará la obra Las aventuras de Pinocho del escritor italiano Carlo Collodi a partir del marco filosófico de la escuela personalista desarrollada en el siglo XX. Se hará énfasis en los conceptos de persona humana, de libertad y del amor como vocación y finalidad de las personas. Se analizará en su conjunto la propuesta axiológica de la obra. Como apoyo complementario de análisis, se utilizará el método lúdico-ambital del filósofo español Alfonso López Quintás para dilucidar las distinciones entre persona y objeto (el primero como fin en sí mismo y el segundo como medio); sentido y significado (lo esencial y exclusivo vrs. lo inmediato y denotativo); el concepto de ámbito (capacidad de fundar realidades creativas) y de encuentro (entre los seres en el que la libertad es primordial); y las categorías de vértigo (posesivo y violento) y éxtasis (apertura y elevación por el amor); acontecimiento y hecho histórico. En su conjunto, este trabajo propone un personalismo literario en el que convergen el arte de la ficción y el arte del pensamiento filosófico. Uno de los principales aportes de este trabajo es mostrar la utilidad de las categorías filosóficas del personalismo para analizar las obras literarias. En el caso concreto de Pinocho se estudiará cómo, a pesar de iniciar experiencias de vértigo, desenfreno, manipulación y cosificación de los seres; Pinocho se transforma en un verdadero ser humano en el que la libertad y el amor tienen la última palabra.
\end{abstract}

Palabras claves: personalismo en literatura, Carlo Collodi, literatura italiana, Pinocho

\begin{abstract}
This paper will examine The Adventures of Pinocchio by Italian author Carlo Collodi from the philosophical framework of the personalistic school developed in the twentieth century. Emphasis will be placed on
\end{abstract}


the concepts of human person, freedom and love as a vocation. An axiological proposal, following Alfonso López Quintás method, helps to clarify the distinctions between: person and object, sense and meaning (that which is essential and that which is denotative), "ámbito" and encounter, vertigo and ecstasy, event and historical fact. This work proposes a literary personalism in which the art of fiction and the art of philosophical thought converge. One of the main contributions of this work is to show the usefulness of philosophical categories of personalism to analyze literary works. In the case of Pinocchio we will study how, despite the initial experience of vertigo (debauchery, manipulation of beings), Pinocchio becomes a real human being in which freedom and love have the last word.

Key words: literary personalism, Carlo Collodi, Italian literature, Pinocchio

\section{Introducción}

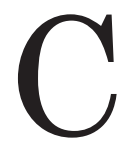
omenta Benedetto Croce que "la madera en que está tallado Pinocho es la humanidad, y él se yergue en pie y entra en la vida como el hombre que emprende su noviciado; fantoche, sí, pero enteramente espiritual" (Benítez 18). En efecto, Pinocho da cuenta de la condición humana, de sus vicios y sus virtudes, de sus deseos y limitaciones. Al ser una obra que aborda la problemática existencial de las personas, trasciende por mucho la mera clasificación de literatura infantil. Es un clásico porque mediante el artificio estético de la palabra logra nadar en las profundidades del alma humana mediante el humor, el ingenio, la aventura y el planteamiento de los grandes temas: la vida, el bien, el mal, la libertad, el amor. Es una obra que hace reír pero también hace pensar. Y es aquí, en la esfera del pensamiento, en la que intentaremos hacer una lectura de la obra a la luz de los principales temas de la filosofía personalista ${ }^{2}$.

\section{La dignidad de Pinocho}

Empecemos por el final: Pinocho se convierte finalmente en un niño de carne y sangre. Esta metamorfosis no es gratuita; tiene historia, pasado de aventuras y desventuras. Es una transformación vinculada a un camino particular para ser persona. En las últimas líneas Pinocho pregunta a Geppetto:

“Cómo se explican todos estos repentinos cambios?

—Estos repentinos cambios en nuestra casa son mérito tuyo.

— ¿Por qué mérito mío?

-Porque cuando los niños que eran malos se vuelven buenos, tienen la virtud de conseguir un aspecto nuevo y sonriente en el interior de su familia (219).

La respuesta de Geppetto evidencia que en sí Pinocho ya tenía la dignidad personal y única de un niño. Lo que ocurre es que era un niño "malo" que no había logrado realizar actos concretos para convertir sus potencialidades 
internas en realidades visibles. El adjetivo "malo" está vinculado con los actos morales de Pinocho no con su dignidad personal $^{3}$. El conflicto-que da desarrollo a la historia- es que Pinocho experimenta una serie de vicisitudes en el camino de aprender a buscar la coherencia de vida entre el ser, el hacer y el pensar, con plena libertad. Sobre este último punto Domínguez Prieto comenta que:

La persona es aquel ser que puede decidir quién quiere ser más allá de sus limitaciones biológicas, psíquicas o sociales. De esta manera, el ser humano es aquel que es capaz de construir su propia realidad. No a partir de la nada, sino justo sobre aquellas dimensiones que condicionan la realidad personal, porque lo que le condiciona es también lo que le posibilita (18).

Precisamente las aventuras de Pinocho son su camino para descubrir su propia identidad personal y construirse a sí mismo a partir de las potencialidades que tiene. Pinocho posee todo lo que el Dr. Juan Manuel Burgos comenta como los aspectos principales del ser persona: tiene inteligencia, libertad, afectividad, dimensión de ser dialógico, corporeidad y necesidades biológicas de primer orden, es capaz de amar y ser solidario, etc. (2008: 24-28). De esta manera, Pinocho desde el principio es un ser con posibilidades interiores $y$ circunstancias externas muy concretas. Aunado a esto, hay que recordar que la persona es un ser inacabado; no nace ya constituido totalmente -cosa que sí ocurre con los meros objetos-, sino que se va haciendo cada día. Esto es lo que le ocurre a Pinocho: sus aventuras son la forma de ir haciéndose; en definitiva, es un ser en construcción.

\section{El ser paradójico}

Otra de las características del ser persona que se muestran en Pinocho es su ser contradictorio. Al respecto Domínguez Prieto comenta:

La persona es un ser paradójico: es un absoluto, pero necesita de las demás personas; es corporal, pero trasciende lo corporal; es algo existente, pero está en construcción; es algo clausurado en sí, pero abierto; es suyo, pero tiene que ir autoposeyéndose; posee una intimidad única que debe construir y llevar a plenitud, pero sólo se realiza saliendo de sí y viviendo la comunidad; es libre para optar por su unificación y plenitud, pero puede optar por su desintegración y empobrecimiento; hace el mal que no quiere y no hace el bien que quiere, etc. (19).

En Pinocho, su ser paradójico está en constante tensión. Por ejemplo, en los primeros capítulos ni siquiera agradece a Geppetto por haberle creado un cuerpo. Al instante ya está fastidiándolo, tomándole la peluca, pateándolo y dándose a la fuga casi de inmediato. El agradecimiento como muestra de apertura personal y cercanía es nulo. Pinocho desde el primer momento está replegado sobre sí mismo. El primer contacto con el Grillo -que será uno de sus consejeros a lo largo de la historiaevidencia esta actitud de replegarse sobre sí, ya que Pinocho actúa de manera posesiva y egoísta al decir que "hoy esta habitación es mía" (48) y al pedirle al Grillo que se fuera de inmediato. Luego de manera violenta lo aplasta. Al día siguiente, Pinocho exclama: “-¡El Grillo parlante tenía razón! Si no me hubiera escapado de casa, y si mi 
papá estuviera aquí, ahora no me moriría de hambre" (52). Aunque fuera por esta necesidad elemental, Pinocho va experimentando que no es un ser autosuficiente, necesita de los demás. Y así, en las diversas aventuras, Pinocho va viviendo esta tensión propia del ser personal.

En la anterior exclamación de Pinocho se evidencia que él sabe intelectualmente qué es el bien y qué es el mal, por eso se lamenta. Se advierte entonces que es un ser consciente de la realidad, pero esto no es suficiente; es necesario que este saber tenga correspondencia con el hacer de sus actos.

\section{Pinocho se hace en la libertad}

Como las grandes historias de la literatura, Las aventuras de Pinocho se tejen a partir de la libertad de la persona. Para el personalismo, la libertad y la responsabilidad se manifiestan en los actos concretos de la persona. La libertad, por su parte, es una característica de la voluntad (Zubiri). En palabras de Domínguez Prieto, la "libertad humana significa capacidad de disponer sobre las tendencias, para organizarlas, negarlas, afirmarlas e incluso dejarse arrastrar por ellas" (44). De esta manera, esta libertad hace de la persona un ser que trasciende aquello que lo determina; está más allá de sus necesidades inmediatas y fundamentales; es el ser con la capacidad de decir "no" a sus impulsos más instintivos.

Precisamente esta definición de libertad responsable es la que Pinocho al principio no vive. Veámoslo con el siguiente ejemplo cuando Mechas, su compañero de escuela, lo invita a irse con él al País de los juguetes:
- No te calientes la cabeza con esas cuitas. Piensa que vamos a un país donde seremos muy dueños de armar alboroto de la mañana a la noche.

Pinocho no contestó, pero lanzó un largo suspiro; por último dijo:

- Hacedme un sitio; ¡voy también yo! (173).

Ciertamente Pinocho elige aquí la opción de irse al País de los juguetes, pero esta elección no la hace con libremente, la libertad apoyada en la razón, la responsabilidad y el bien. Por el contrario, vemos a Pinocho decidiendo con una libertad venida a menos porque elije los valores menores que más bien lo esclavizan a sus apetencias inmediatas. Durante toda la historia, ninguno de los personajes violenta o anula la libertad de Pinocho de elegir entre diversas opciones: los personajes dañinos lo tientan; los que procuran su bien lo exhortan a rectificar; otros al considerarlo una simple marioneta o cosa le restan capacidad de movimiento, pero no libertad interior. Con este panorama, vemos a un Pinocho que se sabe libre, que puede optar, pero que no sabe gestionar dicha libertad de la mejor manera para su bien y el de los demás.

La libertad "acontece en el dominio de sí mismo" (Domínguez Prieto 37). Pinocho en gran parte de sus historias es incapaz de poseerse a sí mismo y esto hace que responsabilice a otros de sus propias desgracias. Por ejemplo, le dice a la marmota que Mechas tiene la culpa de su desventura en el País de los juguetes convertido en burro. Y al principio le dice a Geppetto que el Grillo tenía la culpa de haber muerto porque él no quería matarlo... Esta situación cambia cuando Pinocho asume las exigencias de la otra cara de 
la libertad: la responsabilidad. Esta se evidencia con más fuerza en los capítulos finales, cuando Pinocho rescata a Geppetto del estómago del tiburón y luego, cuando lo cuida y trabaja durante cinco meses para atender las necesidades del viejo padre. En este punto, Pinocho logra dar vida a la libertad "como la capacidad de comprometerse con lo valioso" (Domínguez Prieto 40). Lo valioso en este caso es la relación, la salud y el bienestar de Geppetto que es un ser que necesita atenciones, y Pinocho por amor y gratitud quiere verlo bien y feliz. Este compromiso con lo valioso hace surgir a su vez hábitos positivos como la fidelidad, el trabajo bien hecho, el ingenio; recordemos que Pinocho es ingenioso para buscar maneras de ganar dinero: fabrica canastos y cestos de mimbre, construye una especie de silla de ruedas para sacar a su padre, estudia, lee, etc., hábitos que hacen que Pinocho tenga una serie de ritos cotidianos que le dan sentido a sus días. En definitiva, la libertad responsable ${ }^{4}$ es una de las grandes victorias de Pinocho al final de la historia; en cierta medida esta lo humaniza, lo eleva. En términos de López Quintás, esta libertad que Pinocho conquista es propia de un ámbito de realidad que permite la plenificación de la persona.

\section{Aventuras vertiginosas}

La actitud de vértigo la define López Quintás (1986) como propia de una persona que "polariza su existencia en torno a su yo, y concede primacía a las ganancias inmediatas -a las diversas formas de halago sensorial y de dominio-, suele dejarse llevar de la fascinación cuando se encuentra ante una realidad que le atrae poderosamente" (31). Este es uno de conflictos de Pinocho: es un ser que se deja arrastrar fácilmente por la fascinación del vértigo. Al inicio, cuando Geppetto lo envía a la escuela, de camino escucha una música que lo fascina. Desiste de ir a la escuela y toma el camino por el que se escucha la música (64). Pinocho renuncia a su deber por el deseo atractivo de la música desconocida; el sentido del oído es seducido. Luego descubre que es la música por motivo del "Gran teatro de títeres" (65). Desea entrar, ver y tocar: la seducción de la vista y el tacto. Y entonces vende el abecedario que tanto sacrificio costó a su padre y entra expectante al espectáculo. En este punto el vértigo ha sido asumido por Pinocho de manera pasiva, se ha dejado llevar; no ha querido reflexionar sobre el asunto, ha consentido de la manera más fácil, sin escándalo.

Siguiendo a López Quintás (2011: 39), la fascinación genera euforia, que se transforma en exaltación. Esta saca fuera de sí a la persona y la mueve a unirse al entorno en forma de fusión. Sin embargo, lo que parece tan atractivo finalmente produce decepción, porque el vértigo al principio promete todo, pero acaba quitándoselo todo (3940). Esto le ocurre a Pinocho cuando se entera de que la Zorra y el Gato le han robado las cuatro monedas de oro que había plantado en el Campo de los Milagros: "empezó a excavar con manos y uñas el terreno que había regado. Y excava que te excava, hizo un hoyo tan profundo que hubiera cabido en él un pajar; pero las monedas no estaban. Entonces, presa de la desesperación volvió corriendo a la ciudad (111). Veamos aquí que excavar de esta manera tan desproporcionada es signo de esa 
frustración al verse burlado y engañado. Todo esto empezó por el vértigo de poseer más dinero de manera fácil: la gratificación inmediata de tener en poco tiempo más de dos mil monedas de oro. Aquí hay que salvar el hecho que Pinocho tenía buenas intenciones; deseaba tener más dinero para ayudar a su padre: "Mañana mi padre será un gran señor, porque estas cuatro monedas de plata se convertirán en dos mil" (83). Sin embargo, las rectas intenciones de Pinocho no son consecuentes con los medios para conseguir el dinero; aquí el medio es sospechoso, vertiginoso, inmediato, engañoso. Finalmente se descubre el embuste y Pinocho aprende la lección: el vértigo de las ganancias inmediatas genera muchos problemas, nubla la mente para pensar con detenimiento y deja a la persona en un estado de angustia.

Otra de las aventuras vertiginosas de Pinocho es cuando llega al País de los juguetes. Ahí, en medio de los juegos, la comida, la diversión, el desorden, etc., todas estas actividades sin medida, antojadizas y atrayentes generan en Pinocho una exaltación que lo hace olvidarse de sus compromisos y de las personas que lo aman. Sin darse cuenta pasan cinco meses y de repente, una mañana, le aparecen orejas de burro y luego se transforma completamente en un burro (178). El vértigo le impidió ver con claridad los peligros a los que se exponía. Pinocho embelesado por todas esas atracciones se vio disminuido en su capacidad de razonar, así que los sentidos y los deseos inmediatos le ganaron el pulso a la razón y al deber. Al ver las consecuencias, Pinocho exclama "soy un muñeco sin juicio... y sin corazón” (180).

\section{Amar y ser amado: origen y meta de la vida}

Hemos observado que Pinocho es un ser contradictorio: capaz del bien y del mal, que tiene una dignidad única, que es un ser libre y posee inteligencia, que tiene un sentido del deber. Es un ser en construcción. Las aventuras del joven muñeco alcanzan su sentido último con la realidad del amor. Pinocho es un ser amado y al mismo tiempo, él mismo es capaz de amar.

Por su parte, Juan Manuel Burgos comenta que "el personalismo destaca la prioridad del amor como elemento orientador de la actividad humana $\mathrm{y}$ como acción temática decisiva que da sentido a la vida en el marco de las relaciones interpersonales" (282). Vistas así las cosas, el conflicto que plantean las aventuras de este muñeco de madera radica también en hacer que toda su persona se corresponda con las altas exigencias del amor auténtico. Pinocho es la historia que busca colocar el amor como el rector fundamental de la vida, el referente desde el cual se mira, se decide y se proyecta la persona entera.

Pinocho tiene experiencia del amor principalmente porque se sabe amado por Geppetto y por el Hada. Estos dos personajes encarnan el amor vivo en el cual la persona encuentra siempre consuelo y ayuda. Por esto es que Pinocho, luego de alguna de sus desventuras, en las que ha sido engañado, tomado como "cosa", humillado, etc., desea con más fuerza volver al ámbito de amor de estos dos seres que sí lo aman ${ }^{5}$.

Otro aspecto importante es que el amor es también la vocación principal a la que está llamada la persona. En este sentido, Pinocho es creado por amor y para el amor, y este amor 
siempre llama a la puerta y transforma a la persona cuando esta decide vivirlo de manera radical. En las primeras aventuras, Pinocho dice amar y que cumplirá sus deberes, pero luego se desvía. En los últimos capítulos de la historia es cuando observamos que realmente Pinocho ha decidido amar, y este amor lo transforma desde adentro: cuando va al rescate de su padre, cuando decide cuidarlo y trabajar honradamente para darle el sustento, cuando reconoce y aprecia al Grillo parlante y sus consejos, cuando da su dinero para atender al Hada enferma, etc. De esta manera, Pinocho da vida real al amor mediante sus acciones concretas. En virtud del amor, Pinocho ha logrado la difícil "unidad de vida"6 en la que el ser personal logra su plenitud verdadera.

\section{Conclusión}

Las aventuras de Pinocho nos han permitido ofrecer este breve acercamiento mediante los conceptos y temas de la filosofía personalista. Una de las conclusiones es la riqueza del conflicto planteado: un ser paradójico que debe conquistar la verdadera libertad y orientar su vida de acuerdo con las exigencias del amor. Se pudo evidenciar la transformación interior de Pinocho, que desde el principio es persona pero todavía no es plena: debe conquistarse a sí mismo mediante la libertad.

Finalmente, hemos podido ver la utilidad y la pertinencia de conceptos filosóficos personalistas para una lectura profunda según las posibilidades del texto. Literatura y filosofía no se oponen, sino que son dos formas de acercarse a la compleja realidad. Se demostró que la literatura no es ajena al pensamiento, al planteamiento de las grandes preguntas que la filosofía se plantea desde sus inicios.

\section{Notas}

1 Este trabajo fue presentado en el $I V$ Congreso Internacional de Lenguas Modernas: Por la diversidad lingüistica y cultural, Escuela de Lenguas Modernas, Universidad de Costa Rica, 15-17 de diciembre de 2014. Este trabajo también fue posible gracias al patrocinio de Editorial PROMESA de Costa Rica.

2 Para una mayor comprensión de esta lectura "personalista", remitimos a la obra crítica Literatura y personalismo. Una mirada profunda que reúne 10 estudios que buscan dar cuenta de la riqueza que aporta el personalismo a los estudios literarios.

3 Hay que distinguir entre dignidad personal y dignidad moral; la primera se define por el ser, la segunda por los actos.

4 Para el personalismo, la libertad es uno de los puntos esenciales. Aquí se muestra la recta aclaración que hace $\mathrm{V}$. Frankl en su libro Psicoanálisis y existencialismo, al decir que la verdadera libertad no es una libertad de hacer lo que lo que uno desee-sabiendo que el deseo y los sentimientos son cambiantes-, sino una libertad para ser responsable, para responder de manera positiva a los otros seres personales y a las exigencias propias de la vida.

5 A Pinocho le ocurre lo que ya advertía Orígenes cuando afirma que "¿Quién sabría que la luz es buena si no hubiera sentido las tinieblas de la noche?". El mal que experimenta Pinocho le hace comprender con más profundidad los beneficios del amor del cual se ha alejado. Igual ocurre con la parábola 
del "hijo pródigo" que, alejado de su padre, comprende los grandes beneficios de amor que tenía a su lado, y esto le anima a volver a casa.

6 Expresión de San Josemaría Escrivá para referirse a la coherencia en el pensar, el hablar y el obrar.

\section{Bibliografía}

Benítez, María Esther. "Nota preliminar". Las aventuras de Pinocho. Por Carlo Collodi. Madrid: Alianza Editorial, 2001. 17-36. Impreso.

Buber, Martín. Yo y Tú. Madrid: Caparrós, 1998. Impreso.

Burgos, Juan Manuel., José Luis Cañas y J. Urbano Ferrer, Eds. Hacia una definición de la filosofía personalista. San José: PROMESA, 2008. Impreso.

Introducción al personalismo. Madrid: Palabra, 2012. Impreso.

Cañas, José Luis, Xosé Manuel Domínguez y Juan Manuel Burgos, eds. Introducción a la Psicología personalista. Madrid: Dykinson, 2013. Impreso.

Collodi, Carlo. Las aventuras de Pinocho. Madrid: Alianza Editorial, 1972. Impreso.

Domínguez Prieto, Xosé Manuel. Para serpersona. Madrid:Fundación Emmanuel Mounier, 2008. Impreso.

Frankl, Víktor. El hombre en busca de sentido. Barcelona: Herder, 1991. Impreso.

Gaiba, Gloria. "Pinocho "c'est moi" de Collodi". La comunicación de la belleza a través de la palabra: su actor y su receptor. Actas del VI Encuentro Mesoamericano "Escritura-Cultura" y del IV Coloquio Escritoras y Escritores Latinoamericanos. Ed.
Helena Ospina. San José: PROMESA, 2012. 127-154. Impreso.

Guardini, Romano. Las etapas de la vida. Madrid: Palabra, 2006. Impreso.

- Cartas sobre la formación de sí mismo. Madrid: Palabra, 2009. Impreso.

López Quintás, Alfonso. Literatura francesa del siglo XX. Sartre, Saint-Exupéry, Camus, Anouilh, Beckett. San José: PROMESA, 2011. Impreso.

Ospina, Helena y Gabriel Quesada Mora, eds. Literatura y personalismo. Una mirada profunda. San José: PROMESA, 2014. Impreso.

Porras Castro, Soledad. "En el centenario de Carlo Collodi. Pinocho ayer y hoy". Didáctica. Madrid: Editorial Complutense, 1992. Impreso.

Rodríguez Marugan, Isidoro. "Persona, vocación y compromiso en Emmnuel Mounier". Comunicación presentada en las II Jornadas de la Asociación Española de Personalismo: "La filosofía personalista de Karol Wojtyla", Universidad Complutense de Madrid, 2006. Web. 18 de julio de 2012.

<http://www.personalismo.org/recursos/articulos/rodriguez-marugan-persona-vocacion-y-compromiso-en-emmanuel-mounier/>

Rubio Torres, Carlos. "De cuando Pinocho aprende valores. Una lectura de la novela de Collodi a la luz de las teorías de Shalom H. Schwartz y Leonardo Boff". Revista electrónica Educare. 13. 1. (2009): 7-18. Web. 1 de noviembre de 2014. $<$ http://www.revistas.una.ac.cr/ index.php/EDUCARE/article/ view/1472> 